\title{
A SEGMENTAÇÃO DAS REVISTAS E A TEMÁTICA AMBIENTAL
}

\section{The targeting of the newsmagazines and the environmental theme}

\author{
Eloisa Beling Loose ${ }^{[a]}$, Ilza Maria Tourinho Girardi ${ }^{[b]}$ \\ [a] Jornalista, Mestranda do Programa de Pós-Graduação em Comunicação e Informação da Universidade Federal do Rio Grande \\ do Sul (UFRGS), Porto Alegre - RS, Brasil, e-mail: eloisa.loose@gmail.com \\ [b] Jornalista, Doutora em Ciências da Comunicação, professora no Programa de Pós-Graduação em Comunicação e Informação \\ da Universidade Federal do Rio Grande do Sul (UFRGS), Porto Alegre - RS, Brasil, e-mail: ilza.girardi@ufrgs.br
}

\section{Resumo}

As revistas são lugares privilegiados para a abordagem contextualizada e analítica dos fatos. Também são os meios de comunicação mais segmentados por natureza. Com a grande atenção destinada atualmente aos acontecimentos ambientais, é natural que surjam muitas publicações direcionadas especificamente para essa temática, ainda mais porque as questões ambientais exigem tempo e espaço. Este artigo tem caráter teórico e pretende percorrer as nuances da segmentação de revistas, especialmente no que tange ao interesse (repentino ou não) sobre o meio ambiente. Busca-se resgatar a história desse nicho editorial e apontar características e motivações que permitam a compreensão dessa ênfase temática na contemporaneidade. O jornalismo especializado em meio ambiente ainda carece de discussões que auxiliem na sua institucionalização.

Palavras-chave: Jornalismo especializado. Revistas. Segmentação. Meio ambiente.

\begin{abstract}
The newsmagazines are the privileged spaces for contextualized and analytical approach of facts. They are also the most targeted media, by nature. With the boom of environmental events, it is natural that many publications targeted specifically this theme, especially because environmental issues require time and space. This article has a theoretical character and intends to go through the nuances of targeting magazines, especially the interest (sudden or not) on the environment. It tries to rescue the history of this publishing niche and to point characteristics and motivations that allow understanding this thematic emphasis nowadays. Journalism specialized on the environment question still lacks discussions that help in its institutionalization.
\end{abstract}

Keywords: Specialized journalism. Newsmagazines. Targeting. Environment. 
O objetivo deste trabalho é recuperar as peculiaridades das revistas segmentadas que possuem foco no meio ambiente. As bibliografias e as discussões sobre revistas segmentadas são escassas nos estudos de jornalismo, no entanto, as reflexões que existem devem ser recuperadas à medida que trazem uma luz no processo de entendimento sobre o surgimento de inúmeras publicações especializadas na temática ambiental. O estudo da segmentação auxilia na compreensão do jornalismo que lá está inserido; afinal, ele opera através de um meio, de um veículo, e esses são diferentes, atingindo o público de formas diferenciadas. O jornalismo especializado em certo assunto desenvolve estratégias editorias próprias, oriundas de um público mais seleto e dirigido por uma linha de condução mais rígida, no sentido de ser mais focada.

Ao privilegiar o veículo revista, já se notam tais singularidades. De acordo com Goulart (2006), o perfil do leitor-alvo é um desencadeador de uma série de modificações:

Se a recepção muda, também existem peculiaridades na produção e emissão dos conteúdos: isso inclui a pauta, linguagem, apresentação visual, inclui todo o processo de circulação da informação até chegar ao destinatário. [...] sob esse aspecto, podemos falar de um jornalismo de revista.

Atualmente as revistas representam a maior variedade editorial que se apresenta no mercado da imprensa. Goulart (2006) diz ainda que existem milhares de títulos para todos os públicos e gostos, abrangendo um mercado que corre atrás de nichos de público e de publicidade. A questão da segmentação nesse tipo de veículo já podia ser encontrada nos escritos da Escola de Frankfurt. Conforme Mira (2001), ao pensar em produtos culturais que atingissem um vasto e heterogêneo público, Adorno e Horkheimer já tinham consciência da necessidade de formação de nichos de consumo. Eles afirmaram, na obra Dialética do Esclarecimento, que o mercado divide seus produtos em $\mathrm{A}, \mathrm{B}$ ou $\mathrm{C}$ para melhor captar a todos e, assim, dentro de cada segmento, transformar o indivíduo em um ser genérico.

Com as mudanças na sociedade, a individualização e a produção de bens personalizados, abriram-se caminhos mais férteis para a concepção de materiais jornalísticos voltados para tribos específicas.
Nesse mercado, o custo de elaboração é relativamente mais baixo do que o de outros veículos, sendo que a grande questão para o editor não é tanto como lançar uma revista, mas como mantê-la viva. Afinal, a competição com outras similares resulta em um meio em que a taxa de mortalidade é altíssima. São poucas as que conseguem manter a periodicidade ou ainda persistir nas bancas por um longo período. Mira (2001, p. 11) diz que algumas tendem a se tornar líderes, porém essa é uma posição instável. "Para sobreviver, uma revista tem de acompanhar rapidamente as mudanças do seu público, característica que a torna muito reveladora”, alerta.

É isso que se verifica nas revistas ambientais. Elas surgem em épocas em que o assunto está no auge da discussão pública, mas poucas conseguem resistir às adversidades desse mercado. A dificuldade de dar continuidade à revista, falhando a periodicidade e pecando na repetição de pautas, pode ser decorrente, em grande parte, da falta de verbas publicitárias - já que são poucas as empresas que vêem o público interessado em ecologia como potenciais compradores eidentificados com o escopo da publicação.

\section{CONSIDERAÇÕES SOBRE O VEÍCULO SEGMENTADO}

As revistas surgiram no Brasil no século XVIII. Segundo Scalzo (2003a), a primeira delas surgiu em 1812, na Bahia, com o nome de As Variedades. Em 1817, no Rio de Janeiro, O Propagador das Ciências é tida como a primeira revista segmentada. O veículo dedicado a vários temas, diferentes formatos e com a existência sempre ligada às demandas de cada épocaas que 'ensinavam' às mulheres como ser boas donas de casa, as que traziam os folhetins para entreter, depois as que discutiam política, negócios ou moda e, assim por diante - é, por excelência, o destinado à reflexão, aquele que pode com maior espaço e tempo auxiliar na formação da opinião pública.

As revistas entraram em circulação após os jornais, para ajudar na complementação da educação, no aprofundamento de assuntos, na segmentação, no serviço utilitário que podem oferecer a seus leitores. Scalzo (2003b) afirma que a revista une e funde entretenimento, educação, serviço e interpretação dos acontecimentos. Ela se diferencia por possuir menos informação no sentido clássico (as hard news 
ficam mais a cargo dos jornais diários) e mais informação pessoal (aquela que vai ajudar o leitor em seu cotidiano). Isso não nega o caráter jornalístico do veículo e nem a busca pelo 'furo'. A revista possui outras rotinas produtivas e se articula para trazer a compreensão dos fatos, objetivando informar com qualidade como qualquer outro meio de comunicação. Mesmo assim, a investigação pelo novo, a tentativa de publicar o inédito, corre paralela ao espaço de análise do que já foi divulgado pelo rádio, internet, televisão e/ou jornal.

A partir de meados dos anos 1980, o processo de segmentação da mídia se acelera de modo geral em todo o País. Segundo Mira (2001), no meio revista, segmentado por definição, esse processo torna-se mais intenso e influencia a criação de novas editoras. Com essa mudança, o mercado editorial amplia seus olhares e reparte seus esforços com o propósito de alcançar novos públicos. Em 1985, Thomaz Souto Côrrea (um dos diretores mais importantes da história da Editora Abril) fala em entrevista sobre essa tendência: "Para os empresários, a flexibilização relacionava-se à segmentação na medida em que flexibilizar seria a melhor maneira de se capacitar para descobrir rapidamente novos nichos de mercado" (apud MIRA, 2001, p. 148).

A segmentação está ligada ao processo de globalização, à fluidez do mundo pós-moderno com o qual se depara. O público possui múltiplas identidades que se manifestam de acordo com as condições e situações vividas. O acesso àinformação está internacionalizado e a delimitação de um só tema ou grupo de informações que contemplem um certo público facilita a vida dos indivíduos cercados pela tirania da aceleração do tempo e da velocidade com que se encontram novas notícias. As publicações segmentadas acabam exercendo um papel de selecionador daquilo que pode interessar, poupando o tempo do consumidor de fatos jornalísticos. Conforme Mira (2001, p. 214):

A segmentação é uma estratégia através da qual procura-se atingir novos nichos de mercado. Porém, revela com clareza que as variáveis que recortam os nichos são sociais como, por exemplo, o gênero, a geração ou a questão étnica. Para tornarem-se segmentos de mercado, evidentemente, eles devem ter potencial de consumo.
Assim, a lógica do mercado absorve os movimentos sociais, culturais e demais grupos potenciais de consumidores de informações específicas, mas os rearticula, os 'molda' de acordo com seus interesses mercadológicos. Só haverá nichos de produção editorial se esses trouxerem bons retornos financeiros. Segmentar o mercado é visto como um processo de identificação de interesses e desejos dos leitores. Para tanto, é preciso saber detectar as tendências de comportamento da atualidade, com o intuito de acompanharos movimentos e necessidades do público-alvo.

Regina Sharf (2004) aponta a tematização como uma das mais conhecidas formas de segmentação e vê na versatilidade uma característica que permite a prosperidade desses veículos. A partir de um tema central, a exemplo do meio ambiente, surgem revistas que se pautam essencialmente a fim de contemplar o interesse desses leitores. Atenta-se para o fato de que, às vezes, os realizadores não são jornalistas. Ocorrem casos em que são os especialistas ou apaixonados por uma temática que impulsionam o projeto, sendo daí assessorados por profissionais do meio midiático.

A busca por matérias cada vez mais relacionadas com o assunto presente no dia-a-dia do leitor ou aquele diretamente vinculado a suas curiosidades, planos ou preocupações tornou-se uma realidade na delimitação de públicos no mercado jornalístico contemporâneo. Eurípedes Alcântara (apud CALDAS, 2002, p. 156) sublinha essa tendência: "a especialização crescente das publicações não-noticiosas, sua divisão e subdivisão em assuntos cada vez mais específicos é inescapável. Este é um imperativo mercadológico."

Além do fato de a revista ser o veículo mais segmentado dentre os meios de comunicação, ela possui a mesma vantagem do jornal quanto à questão do suporte. Ambos são impressos - e o que é impresso, historicamente, parece mais verdadeiro do que aquilo que não é. A palavra impressa incute maior veracidade, legitimidade e tem caráter documental e comprobatório. A escrita é o meio mais eficaz para transmitir informações complexas. A profundidade das informações está intimamente relacionada às páginas de revista.

A periodicidade semanal, quinzenal ou mensal possibilita a análise e transmissão de informações mais intrincadas. O maior tempo de apuração da notícia (de investigação dos fatos) corrobora 
para uma análise mais complexa e contextualizada daquilo que o jornal noticiou de um dia para o outro. Além de informar, elas entretêm, trazem análise, reflexão, concentração e experiência de leitura. A segmentação traz ainda outra vantagem: possibilita que aqueles que a produzem possam delinear de forma muito próxima para quem estão escrevendo. Nenhum outro meio de comunicação pode definir melhor seus leitores ideais que as revistas segmentadas.

Baseado no que foi exposto, as revistas segmentadas possibilitam aliar fatos comuns que contemplem as expectativas de um grupo de leitores bem definidos, com profundidade e variedade. As revistas especializadas proporcionam uma relação diferente com quem as lê: traz uma grande quantidade de fatos de total interesse, junto à questão afetiva (daquele que coleciona, que relê, que leva para mostrar para os amigos etc).

\section{COBERTURA AMBIENTAL NOS MEIOS DE COMUNICAÇÃO}

A mídia já dá atenção aos fatos ambientais; entretanto, economia, política e esportes costumam alavancar maiores equipes de profissionais e despertar maior interesse nos editores. $\mathrm{O}$ meio ambiente é uma pauta pouco aprofundada nos meios de comunicação informativos (os não especializados), tanto que quando se dá algum acontecimento temse dúvida de onde inseri-la. Por ser um assunto de faceta multidisciplinar, pode ser desdobrado nas mais variadas editorias.

Esse descaso é antigo e não é exclusivo da imprensa brasileira. O sociólogo John Hannigan (1995, p. 85) declara que nos Estados Unidos a preocupação com a conservação já existia desde 1880, porém o dogma central do ambientalismo - de que tudo está ligado a tudo o resto - pareceu ser difícil de compreender em termos jornalísticos. "Os assuntos abordados nessa época eram específicos e tratados como somente problemas locais". Segundo esse autor, derramamentos de óleo, enchentes, queimadas, e demais acidentes ambientais eram noticiados, entretanto, sem as devidas considerações e repercussões. A cobertura inicial era pontual e bastava-se com as respostas do tradicional lead somado a relatos dos 'especialistas'.

Durante o fim dos anos 1960 e princípios dos anos 1970, a mídia aumentou drasticamente o espaço dado ao meio ambiente. Nesse período, "pela primeira vez, as questões ambientais foram vistas pelos jornalistas na Grã-Bretanha e na América como uma categoria principal de notícias" (HANNIGAN, 1995, p. 85). A mudança de consciência deveu-se, em boa parte, pela visão que se teve da Terra a partir da lua, em 1969. Com a imagem do globo terrestre, até então desconhecida e não-imaginada, o meio ambiente ganhou destaque na esfera pública.

Contudo, depois desse despertar, a cobertura desse tema começou a decair. Até os anos 1980 as notícias ambientais continuam a ser específicas e ter importância apenas local. Hannigan (1995) avalia que só na década seguinte as histórias sobre o tema ganham um caráter mais global e complexo.

No Brasil, acompanhando os rumos mundiais, o tratamento dos fatos ambientais também demorou a ser considerado. A cobertura ambiental brasileira só teve seus dias de glória quando eventos ambientalistas de grande porte aconteceram aqui, a exemplo das conferências internacionais Rio $92 \mathrm{e}$ Rio +10 . Nesse período, ocorreu intenso debate na sociedade sobre temas de interesse ambiental e a mídia mobilizou-se em favor da causa.

Seguiram, no entanto, momentos de encolhimento, nos quais o meio ambiente parecia ser desinteressante para todos. Tal desestímulo, apontado no Manual de Comunicaşão e Meio Ambiente por Hamú e Gontijo (2004), pode ser atribuído a crises financeiras e de gestão dos veículos de comunicação, que invariavelmente diminuem os espaços jornalísticos sobre o assunto. Outro fato é a substituição de jornalistas experientes por repórteres iniciantes (e, assim, mais baratos), resultando em coberturas superficiais e fragmentadas, muitas vezes limitadas a desastres ambientais ou temas polêmicos.

O meio ambiente na mídia brasileira passa por movimentos sazonais, que refletem mais a posição secundária com a qual o tema tem se inserido na agenda de prioridades de governos, empresas e demais segmentos.

A transversalidade do tema, proposta por ambientalistas e incorporada ao discurso do governo, ainda não ganhou corpo: as preocupações ambientais continuam restritas ao Ministério do Meio Ambiente e ao Ibama, enquanto os demais ministérios ligados à produção seguem com sua agenda desenvolvimentista tradicional, nada sustentável. O reflexo disso 
pode ser observado em algumas redações, que permanecem fiéis à velha visão compartimentalizada de mundo, onde o que importa, em geral, é a política, a economia, o esporte e o 'resto' - nesta categoria está incluído o tema "meio ambiente" (HAMÚ; GONTIJO, 2004 apud BELTRAND, 2004, p. 9).

Na última década, após inúmeros desastres e uma conscientização maior dos jornalistas, empresários e políticos, abriram-se espaços específicos para o tema e surgiram revistas voltadas somente para tratar da temática. Mesmo com os avanços, ainda se encontram muitas notícias isoladas de contexto e delineadas por causa de eventos (onde são consideradas a presença de celebridades e o simbolismo), de catástrofes ambientais e de acontecimentos jurídicos administrativos (audições parlamentares, alterações de leis ambientais, lançamentos de livros, etc) ${ }^{1}$. Além disso, o uso de fontes lattenizadas (expressão derivada de BUENO, 2007), isto é, fontes do meio científico, permanece recorrente nas matérias ambientais. O viés da divulgação científica é forte quando se observa o meio ambiente nos meio de comunicação.

Outro ponto que se repete é o apelo às histórias de interesse humano que sempre despertaram o público. O drama, o desespero, a perda, a dor e a esperança são elementos que sempre fizeram vender jornais e revistas. Portanto, os desastres ambientais acabam por se mostrar uma bela oportunidade para arrecadar mais lucros e aumentar a visibilidade dos veículos. Não restam dúvidas de que, embora demonstre traços sensacionalistas, esse tipo de cobertura incita o debate público. Vale lembrar que também há outro lado: elas favorecem enquadramentos monocausais, em vez de enquadramentos que envolvem redes causais longas e complexas.

Enquanto a cobertura centrada nos acontecimentos tem a vantagem de aumentar a consciência pública dos tópicos ambientais de outra forma esquecidos, tem igualmente o seu lado negativo. Ao centrar-se em acontecimentos discretos, em vez de nos contextos em que eles ocorrem, os meios de comunicação tendem a dar aos consumidores de notícias a impressão de que os indivíduos ou corporações errantes são responsáveis por esses acontecimentos, em vez das políticas institucionais e dos desenvolvidas sociais (SMITH, 1992; WILKINS; PATTERSON, 1990 apud HANNIGAN, 1995, p. 89).

Dessa forma, percebe-se que a mídia necessita equilibrar os tipos de cobertura sobre meio ambiente. O acesso à informação é um direito fundamental, pois receber informações de boa qualidade permite à sociedade tomar decisões conscientes. Espera-se que os meios de comunicação cumpram sua função buscando a pluralidade de fontes, a variação de enfoques e a problematização nos assuntos que não estão evidentes. $\mathrm{O}$ meio ambiente não tem apenas uma causa, uma consequência, um expert, um caminho possível.

\section{O MEIO AMBIENTE NAS REVISTAS ESPECIALIZADAS}

É difícil saber como surgiram as revistas especializadas em meio ambiente. Os registros são poucos. Até as revistas ambientais que circulam hoje em dia possuem poucas informações sobre quem as produz, quais linhas editoriais seguem, com que propósitos foram fundadas. Nas pesquisas bibliográficas feitas, notou-se que na década de 1990 o meio ambiente aparece nas segmentações ligadas à aventura, ao comportamento (relacionado ao estilo de vida 'verde') e ao turismo ecológico.

Pensando no modo de produção, as revistas especializadas, a priori, passam pelas mesmas fases de elaboração de qualquer produto jornalístico: construção da pauta, apuração dos fatos, hierarquização das informações, escolha de fotografias e/ou ilustrações, diagramação/editoração e revisão. As singularidades estão centradas no maior espaço de tempo que se tem para chegar ao resultado (tendo-se, por isso, maior responsabilidade quanto à exposição dos contextos, análise dos acontecidos e explicações mais complexas), no delineamento mais concreto do público e na definição 'macro' do que a revista abordará nas edições seguintes. A revista é o espaço das grandes reportagens, e as voltadas para o meio ambiente costumam conter matérias de mais de três

1 Classificação encontrada na obra Sociologia Ambiental, de John Hannigan. 
páginas buscando explicitar a visão holística que o tema requer.

A lucratividade também é diferenciada. Mira (2001, p. 161) expõe um pouco da dinâmica que rege uma grande parte das revistas segmentadas:

[...] Trata-se de produções independentes, elaboradas por pequenas editoras, montadas com amigos ou parentes. A equipe de redação é mínima, contando com artigos e matérias de colaboradores também ligados ao meio. Essas publicações, naturalmente, não têm a estabilidade de grandes editoras: elas aparecem tentando captar oportunidades editoriais de acordo com as modas esportivas e desaparecem com elas; mas quando bem sucedidas (ou seja, se tiverem potencial para chegar perto de 100 mil exemplares), podem ser compradas ou associar-se a uma grande editora [...]. Seu desaparecimento no mercado editorial aponta para a tendência contemporânea de descentralização da produção na mídia em geral, no cinema, na televisão, na indústria fonográfica, permanecendo os grandes conglomerados com as etapas mais lucrativas, ou seja, o marketing da distribuição.

A questão financeira atinge todo o mercado jornalístico. Para manter jornalistas nas redações e pagaros custos das rotinas produtivas necessita-se de dinheiro. As revistas segmentadas em meio ambiente possuem ainda um público restrito e são poucas as que mantêm assinantes fiéis. Encontram-se hoje nas bancas de revistas que só se sustentam de venda avulsa e de publicidade. Essa afirmação explica por que algumas revistas ambientais abusam de capas que estampem catástrofes: aquilo que é assustador e causa receio vende mais que uma capa com um lobo-guará ou um lago bem conservado. Os saldos publicitários também são pequenos ainda, devido às contradições existentes entre os produtores, defensores de uma nova visão de planeta, e os investidores, preocupados com a arrecadação de mais consumidores. Expor os problemas ambientais implica revelar os responsáveis, e às vezes tais responsáveis são justamente os que mantêm as empresas jornalísticas. Pode-se imaginar que muitas empresas sofram constrangimentos, ou até impedimentos, quando se trata de discutir a imagem de quem banca os salários dos jornalistas. Trigueiro expõe (2005, p. 295):
É fato que o jornalismo ambiental ameaça os interesses das empresas públicas ou privadas que agem na contramão da sustentabilidade. Para essas empresas, uma exposição ruim na mídia pode desencadear uma sucessão de desastres que vão de um ligeiro arranhão na imagem à perda da credibilidade - com eventuais impactos no faturamento e na cotação de ações no mercado de Bolsa.

Porcausa desseimpasse, sãoas Organizações Não Governamentais (ONGs) que contribuem de forma mais assídua na manutenção de tais publicações. É claro que esse quadro está se transformando desde a implantação de normas que exigem das empresas cuidados em relação à sustentabilidade de suas ações. Com o cumprimento rígido das leis ambientais e com o desenvolvimento de certificados que valorizem as práticas ambientais no meio empresarial, o termo 'ecologicamente correta' passou a dominar os slogans de fábricas e prestadoras de serviço. O que antes era ignorado - por não trazer benefícios rentáveis - passou a ser marketing 'verde'. Os incentivos fiscais e as exigências dos consumidores ecologicamente responsáveis firmaram um perfil empresarial mais consciente, ainda que a compreensão do que seja ecológico tenda a ser rasa e sofra pressões constantemente em prol de lucros.

As revistas ambientais brasileiras se deparam com esse problema econômico. Nota-se que as redações são enxutas pela grande quantidade de matérias assinadas por um único repórter ou pelo espaço significativo que é cedido às colunas de opinião escritas por biólogos, geógrafos e demais especialistas. A falta de periodicidade, como é o caso da Aquecimento Global, ou o longo tempo que separa uma edição da outra, como a revista Mãe Terra, que é bimestral, são pistas dessa situação.

É preciso levar em conta que a consciência ecológica é recente e engatinha nas redações jornalísticas. No fim dos anos 1970 e início dos anos 1980 a imprensa brasileira deu destaque para a cobertura ambiental, divulgando denúncias sobre o desmatamento na Amazônia e a contaminação dos solos e água pelo uso de agrotóxicos em decorrência do modelo agrícola implantado. $\mathrm{Na}$ realização da conferência internacional Eco-92, no Rio de Janeiro, o jornalismo abriu mais os olhos para as questões ambientais. Mira (2001) conta que, nesse ano, a Editora Azul lançou Os Caminhos da Terra - revista 
de turismo de 100 mil exemplares dirigida ao viajante interessado em descobrir lugares não frequentados, em explorar a natureza. Essa foi uma das pioneiras e estava baseada no tripé aventura/ natureza/ecologia, sendo que o caráter de desbravador das matas era o atrativo principal. Os anunciantes já se enquadravam no pensamento do "marketing ecológico" ou "marketing verde", ou seja, empresas que querem criar uma imagem pró-ecológica apoiando determinadas causas ou mostrando que seus produtos não contribuem para a destruição da natureza. O público-alvo era aquele aventureiro, que sonhava em ter uma vida alternativa em meio à natureza.

Nessa mesma época, surgiram publicações editadas por organizações não governamentais como o Jornal do Meio Ambiente o o JornalTerramérica. Revistas digitais também apareceram - já que a internet possibilita menores custos de produção e veiculação e, assim, fica mais independente de anunciantes-, como a Água Online e a Rede Verde. Das publicações que atingem um número maior de leitores, são registradas duas: Eco 21 e Ecologia e Desenvolvimento.

A Eco 21 foi inspirada na Rio-92, em 1990, e tinha como linha mestra a documentação do processo de implementação da Agenda 21 e das convenções, assinadas durante o encontro de cunho ambiental. Primeiro tinha o nome de ECO-RIO, mas foi renomeada após o fim da conferência e demarcou um novo olhar sobre os estudos na área ambiental. $\mathrm{O}$ produto foi fruto da associação entre a Tricontinental Editora e Andino Cultural e tinha como objetivo documentar iniciativas de âmbito local, regional, nacional e internacional, que se encaminham para a implementação dos princípios do desenvolvimento sustentável. Zamberlan (2004, p. 33) assim descreve a revista:

Estruturada em 50 páginas ou encontrada no site www.eco21.com.br, a 'Eco 21' adota uma visão crítica da realidade, propondo uma análise dos fatos do ponto de vista do ambientalismo de esquerda. As pautas, que procuram abordar os principais acontecimentos nacionais e internacionais, tratando da implementação da sustentabilidade, são discutidas entre os seis jornalistas da redação de 'Eco 21' e transcritas nos artigos dos colaboradores, que se utilizam das páginas da revista para veicular as suas idéias e iniciativas. A seqüência na ordem das reportagens prioriza a política ambiental. Em seguida, os grandes eventos ou acontecimentos, reportagens de assuntos específicos, fatos científicos, ecoturismo e cultura são diagramados no padrão de duas colunas e uma falsa ou, no caso das reportagens de opinião, em duas colunas largas.

Para a mesma autora (2004), a eclosão das ideias sobre desenvolvimento sustentável e meio ambiente fez com que a Editora Terceiro Mundo (hoje Terceiro Milênio), nascida em 31 junho de 1980 e com paternidade atribuída ao jornalista e deputado federal Neiva Moreira, lançasse três publicações no mercado com esta ênfase: Cadernos do Terceiro Mundo, Ecologia e Desenvolvimento (1991) e Revista do Mercosul (1992). A revista Ecologia e Desenvolvimento foi a que mais teve sucesso entre as três. De acordo com Zamberlan (2004, p. 31):

As quarenta e oito páginas da revista abordam a temática ambiental por meio de textos, fotografias e ilustrações. Em toda edição há uma reportagem de capa, geralmente escrita entre as páginas 14 e 21. Em comemoração à centésima edição da revista, em março de 2002, 'Ecologia e Desenvolvimento' ganhou um número especial, onde o seu histórico foi retomado entre as setenta e duas páginas da publicação de aniversário.

Embora o tema meio ambiente esteja circulando nas bancas com mais intensidade desde os anos 1990, percebe-se que as revistas especializadas ainda são poucas e que as mais antigas não sobreviveram aos anseios do mercado editorial da última década. Se olharmos as bancas de revistas hoje, verificaremos que o tema ecológico circula desde as publicações especializadas em economia, às informativas semanais, passando pelas científicas, espiritualistas até chegar às de comportamento.

No veículo revista o 'verde' aconselha a mudanças de hábitos mais responsáveis e à compra de equipamentos eletrônicos fabricados por empresas sustentáveis, diz ao leitor como economizar luz, água e se alimentar de forma mais saudável, explica os fenômenos que mais repercutem na mídia eletrônica. Cilene Victor da Silva, diretora da revista Com Ciência Ambiental, alega em entrevista que a publicação está “entre o jornalismo denuncista, preso às tragédias, e aquele vendido às instituições do 
discurso sustentável” (apud BUENO, 2007, p. 163), ao se referir à cobertura do jornalismo ambiental.

Essa afirmação pode ser verificada quando se analisa o conteúdo e a forma com que o meio ambiente é discursivamente construído para o leitor. Em geral, os veículos especializados tomam mais cuidados quanto aos termos e formas de elaboração das notícias que a mídia generalista, até porque os profissionais que cotidianamente cobrem o tema possuem maior repertório de conhecimento para questionar os especialistas do que aqueles que esporadicamente se defrontam com o assunto. No entanto, a comunicação ambiental é vista, num primeiro nível, como um discurso científico objetivado. Ou seja, as reportagens ambientais confundem-se com a divulgação científica, com a promoção de pesquisas $\mathrm{e} /$ ou instituições que as fazem.

Nesse caso, os meios de comunicação negligenciam um discurso humano de interesse, o que desloca o jornalista para fora da ação orientada dos movimentos e políticas sociais. Constata-se que a união entre os experts oriundos do campo científico e o lado humano, da experiência, tem dificuldades de se equilibrar nas matérias ambientais. Os extremos são mais fáceis de localizar: a tradução de um trabalho científico feito para um público supostamente leigo ou a dramatização de vítimas de uma catástrofe. Ambos isolados e relevantes pelo momento. Um pecando pelo lado cientificista e o outro pelo excesso de dor humana.

Mediante a ênfase da legislação e das oportunidades mercadológicas para os empresários sustentáveis, encontra-se também o discurso ambiental na mídia apresentado como uma forma de empreendedorismo empresarial. Situações diferentes são verificadas apenas em veículos especializados em meio ambiente, que são poucos e, como se viu, enfrentam dificuldades para manter-se.

Não se pode dizer aqui que as revistas ambientais são os exemplos ideais de jornalismo ambiental (afinal, o que se coloca é somente fruto de observação que é comprovada a partir da revisão bibliográfica), porém, dentre as formas de se explicar e compreender as questões referentes ao meio ambiente, elas se destacam pela profundidade e capacidade de dar múltiplos enfoques. Refletindo-se sobre os pressupostos do jornalismo ambiental, que precisa entender da complexidade e amplitude das temáticas ambientais e transcrevê-las para os públicos de maneira simples sem comprometer a essência da informação, em espaços cada vez mais reduzidos, em velocidades cada dia maiores e ainda procurando cuidando para não ser irritantemente didático e talvez até pedante, vê-se que as revistas especializadas são um espaço privilegiado para o exercício dessa prática, que implica a compreensão de inúmeros fatores. André Trigueiro (2005, p. 292) reforça essa ideia quando diz que "uma das premissas do Jornalismo Ambiental é perceber a realidade que nos cerca de um ângulo mais abrangente, privilegiando a qualidade de vida no planeta e do planeta".

\section{CONSIDERAÇÕES FINAIS}

Com o que foi posto tentou-se relacionar os aspectos das revistas especializadas com as particularidades do jornalismo ambiental. A segmentação buscou ser delineada a fim de mostrar quão fértil é esse espaço para o esclarecimento e compreensão do meio ambiente, mesmo que enfrente barreiras mercadológicas que afetem sua constância e tradição histórica.

Os pontos de discussão levantados neste artigo pretendem abrir caminhos para trabalhos mais aprofundados, já que a segmentação das revistas é algo pouco pesquisado no campo da comunicação ainda. A articulação com a temática ambiental foi válida na medida em que as respostas do funcionamento desses veículos especializados respondem a uma série de deficiências e falhas que é possível detectar nas suas coberturas ambientais.

Assim, a pesquisa bibliográfica realizada mostrou-se essencial para o entendimento dos mecanismos das revistas segmentadas que se voltam para a temática ambiental e serviu como um mapeamento de indagações, já que surgiram muitas dúvidas. Sentiu-se a necessidade de um levantamento das publicações ambientais brasileiras que já existiram e investigar as causas de suas mortandades, conhecer e entender as intenções das editoras que as publicam, procurar dados mais concretos sobre o perfil do público e resgatar o histórico dessas revistas. Espera-se que este artigo seja um primeiro passo para estudar com mais afinco essas questões e que futuras investigações contribuam com informações mais precisas sobre a trajetória de revistas de conteúdo ambiental e apontem soluções para o alcance e sua longevidade. 


\section{REFERÊNCIAS}

BUENO, W. Comunicação, jornalismo e meio ambiente. São Paulo: Marajoara, 2007.

CALDAS, Á. (Org.). Deu no jornal: o jornalismo impresso na era da internet. São Paulo: Loyola, 2002.

GOULART, A. Uma lupa sobre o jornalismo de revista. Observatório de Imprensa, São Paulo, PROJOR Instituto para o Desenvolvimento do Jornalismo, ano 14, n. 388, 07 jul. 2006. Disponívelem: < http://www.observatoriodaimprensa.com.br/artigos.asp? $\operatorname{cod}=388 \mathrm{DAC} 001>$. Acesso em: 11 jun. 2008.

HAMÚ, D.; GONTIJO, M. J. Apresentação. In: BELTRAND, M. V. de. (Org.). Manual de comunicação e meio ambiente. São Paulo: Peirópolis, 2004. p. 9-10.

HANNIGAN, J. Sociologia ambiental: a formação de uma perspectiva social. Lisboa: Instituto Piaget, 1995.

MIRA, M. C. O leitor e a banca de revistas: a segmentação da cultura no século XIX. São Paulo: Olho d'Água/ FAPESP, 2001.

SCALZO, M.Jornalismo de revista. São Paulo: Contexto, 2003a.

Por que as revistas existem, abrem e fecham. Observatório de Imprensa, ano 14, n. 245, 07 out. 2003b. Disponível em: < http:/ / www.observatoriodaimprensa.com. br/artigos/al071020031.htm>. Acesso em: 10 jun. 2008.
SHARF, R. O jornalismo impresso. In: BELTRAND, M. V. de. (Org.). Manual de comunicação e meio ambiente. São Paulo: Peirópolis, 2004. p. 69-76.

TRIGUEIRO, A. Mundo sustentável: abrindo espaço na mídia para um planeta em transformação. São Paulo: Globo, 2005.

ZAMBERLAN, L. Comunicação e meio ambiente na mídia impressa: poder, cultura e ideosfera - um diálogo complexo. 2004. 209 f. Dissertação (Mestrado em Comunicação) - Pontifícia Universidade Católica do Rio Grande do Sul, Porto Alegre, 2004.

Recebido: 26/10/2008

Received: 10/26/2008

Aprovado: 30/01/2009

Approved: 01/30/2009

Revisado: 07/01/2010

Reviewed: 01/07/2010 